\title{
(2) OPEN ACCESS \\ Low risk of necrotising enterocolitis in enterally fed neonates with critical heart disease: an observational study
}

\author{
Kajsa Nordenström, ${ }^{1,2}$ Katarina Lannering, ${ }^{1,3}$ Mats Mellander, ${ }^{1,3}$ Anders Elfvin (D) ${ }^{1,2}$
}

\begin{abstract}
${ }^{1}$ Department of Pediatrics, Institute of Clinical Sciences, Sahlgrenska Academy, Goteborg, Sweden

2Department of Pediatrics, Sahlgrenska University Hospital, Goteborg, Sweden

${ }^{3}$ Pediatric Heart Center, Sahlgrenska University Hospital, Goteborg, Sweden
\end{abstract}

\section{Correspondence to}

Dr Anders Elfvin, Department of Pediatrics, Institute of Clinical Sciences, Sahlgrenska Academy, Goteborg 416 85, Sweden; anders.elfvin@vgregion.se

Received 15 November 2019 Revised 13 February 2020 Accepted 20 February 2020 Published Online First 13 March 2020

\section{Check for updates}

(C) Author(s) (or their employer(s)) 2020. Re-use permitted under CC BY-NC. No commercial re-use. See rights and permissions. Published by BMJ.

To cite: Nordenström K, Lannering K, Mellander M, et al. Arch Dis Child Fetal Neonatal Ed

2020;105:F609-F614.

\section{ABSTRACT}

Objective We aimed to investigate the frequency of necrotising enterocolitis (NEC) in infants with critical congenital heart disease (CCHD) hypothesising that preoperative enteral feeding does not increase the risk of NEC.

Background When NEC affects term infants, underlying risk factors such as asphyxia, sepsis or CCHD are often found. Due to fear of NEC development in infants with CCHD great caution is practised in many countries to defer preoperative enteral feeding, but in Sweden this is routinely provided.

Design, setting and patients An observational study of all infants born with CCHD who were admitted to Queen Silvia Children's Hospital in Gothenburg between 2010 and 2017. The International Classification of Diseases 10th Revision diagnosis code of NEC was used to identify NEC cases in this group. Infants described as 'fully fed' or who were fed at least $45 \mathrm{~mL} / \mathrm{kg} /$ day before cardiac surgery were identified.

Main outcome measures NEC in infants with CCHD in relation to preoperative enteral feeding.

Results There were 458 infants with CCHD admitted during the study period. 408/458 were born at term and $361 / 458$ required prostaglandin E1 before surgery. In total, 444/458 infants (97\%) were fully fed or fed at least $45 \mathrm{~mL} / \mathrm{kg}$ daily before cardiac surgery. Four of 458 infants developed NEC (0.9\%). All four had other risk factors for NEC.

Conclusions This study showed a low risk of NEC in term infants fed enterally before cardiac surgery. We speculate that preoperative enteral feeding of neonates with CCHD does not increase the risk of NEC development.

\section{INTRODUCTION}

Necrotising enterocolitis (NEC) is a serious bowel disease that mainly affects preterm infants, usually at 1-2 weeks of age. Infants born preterm have an immature immune response, a weak barrier function and an abnormal intestinal bacterial microflora. These circumstances are thought to increase the risk for NEC. The disease is characterised by inflammation in the wall of the bowel that may lead to ischaemia and perforation. ${ }^{1-3}$ The immaturity of the epithelial barrier and damage to the mucosa, for example, caused by ischaemia, provides conditions that facilitate intestinal bacterial invasion through the bowel wall resulting in inflammation. ${ }^{4}$

When NEC affects term infants, underlying factors such as asphyxia, sepsis and critical congenital heart

\section{What is already known on this topic?}

- Many practitioners avoid enteral feeding before cardiac surgery in newborns with critical congenital heart disease due to concern of the development of necrotising enterocolitis.

- Swedish infants with critical congenital heart disease are routinely fed enterally before cardiac surgery.

\section{What this study adds?}

- In a large Swedish cohort of newborns with critical congenital heart disease who received enteral feedings prior to cardiac surgery, the rate of necrotising enterocolitis was very low.

- This suggests that preoperative enteral nutrition in this population is not associated with the development of necrotising enterocolitis.

disease (CCHD) are often to be found. ${ }^{5}{ }^{6}$ Due to fear of NEC development in infants with CCHD, great caution to defer preoperative enteral feeding is practised in many countries and total parental nutrition (TPN) is provided instead. ${ }^{7}$ In previous studies, the frequency of NEC in infants with CCHD varies between $3 \%$ and $9 \%$, with no clear relationship to preoperative feeding practices. ${ }^{8-11}$

In Sweden, preoperative enteral feeding, with breast milk or formula, is routinely provided to stable infants with CCHD. Postoperative enteral feeding is initiated as soon as possible after surgery, usually within the first 1-2 days. We aimed to study whether infants born with CCHD who were enterally fed prior to cardiac surgery had an increased risk of NEC compared with the results of previous studies.

We hypothesised that preoperative enteral feeding does not increase the risk of NEC in infants with CCHD.

\section{METHODS}

For the purpose of this study, CCHD was defined as cardiac defects requiring cardiac surgery and/ or interventional catheterisation before 2 months of age or causing death before 2 months of age without such treatment. The infants were identified using the International Classification of Diseases 10th Revision (ICD-10) codes for the following 
diagnoses: aortic stenosis, coarctation of the aorta (CoA), interrupted aortic arch, hypoplastic left heart syndrome (HLHS), mitral stenosis, transposition of the great arteries (TGA), pulmonary stenosis, tetralogy of Fallot (ToF), double outlet right ventricle, pulmonary atresia (with or without ventricular septal defect), tricuspid atresia, hypoplastic right ventricle, truncus arteriosus, double inlet left ventricle, total anomalous pulmonary venous return and Ebstein's anomaly. Between 1 January 2010 and 31 December 2017, a total of 860 infants with at least one of these diagnoses were admitted to either the cardiac unit, neonatal intensive care unit or paediatric intensive care unit at the Queen Silvia Children's Hospital in Gothenburg, Sweden. All subjects were either inborn or transferred from other hospitals within our referral area for paediatric cardiac surgery corresponding to approximately half of the Swedish population. From this group, 458 infants satisfying the above criteria for CCHD were identified. We did not search for infants who died at home who were diagnosed with CCHD postmortem, or infants with CCHD who died in a referring hospital before referral.

Infants who had been fed significant amounts of either breast milk or formula enterally before heart surgery were identified. In the hospital charts they were described as 'fully fed' (100$150 \mathrm{~mL} / \mathrm{kg}$ daily) or fed at least $45 \mathrm{~mL} / \mathrm{kg}$ daily. The ICD-10 diagnostic code for NEC (P779), which includes both medically and surgically treated NEC, was used to investigate the NEC frequency. This was crosschecked against the local paediatric surgery register without any additional NEC or suspected NEC cases being found. A chart review was performed, collecting demographic data including gestational age, birth weight, prenatal diagnosis of the cardiac defect, treatment with prostaglandin E1 (PGE1), feeding regimen, age at surgery or catheter intervention, and mortality.

\section{RESULTS}

The largest diagnostic groups among the 458 infants with CCHD were CoA $(n=126)$, TGA $(n=103)$, HLHS $(n=47)$, pulmonary atresia $(n=34)$, pulmonary stenosis $(n=33)$ and aortic stenosis $(n=32)$ (table 1). The total study group either underwent cardiac surgery $(n=398)$, interventional catheterisation $(n=48)$ or died without such treatment $(n=12)$ before 2 months of age (table 1$)$. Of the 458 infants, 19 patients had their first cardiac intervention within the first 2 days of life, 209 within the first week, 290 during the first 10 days and 391 during the first 31 days. The median postnatal age in days at cardiac surgery/catheter intervention for each diagnostic group is shown in table 1 . The total number of deaths in the cohort was 46/458, of whom 34/46 had undergone either surgery or interventional catheterisation. Twelve of 34 died within 30 days of surgery and 22/34 died later. Last follow-up was in May 2018. The median follow-up time was 4 years (range $0.5-8$ years). Eighty-nine per cent (408/458) of the infants in the cohort were born at term $(\geq 37+0$ weeks). No infant was born before $28+0$ weeks, 4 between $28+0$ and $29+6$ weeks, 19 between $30+0$ and $34+6$ weeks and 22 between $35+0$ and $36+6$ weeks. Data on gestational age and birth weight were missing in five cases. Twenty-eight per cent (127/458) were prenatally diagnosed and HLHS was the diagnostic group in which the frequency of prenatal diagnosis was most prevalent (34/47) (table 1).

In total, 97\% (444/458) received significant enteral feeding volumes before cardiac intervention or death. Of these, $91 \%$ (404/444) were fully fed and 9\% (40/444) were fed at least $45 \mathrm{~mL} / \mathrm{kg}$ daily. Three per cent (14/458) were not fed enterally at all before cardiac intervention or received amounts less than $45 \mathrm{~mL} / \mathrm{kg} /$ day. Thirty-four per cent were fed breast milk only, $12 \%$ formula only and the rest a mix of breast milk and any amount of formula. The majority of these infants received minimal amounts of formula initially, and were then fully breast fed. Hence, $88 \%$ of the infants were at least partially receiving breast milk. The formula used was regular formula for newborn infants. The breastfed infants were fed on demand. The bottle, or gastric tube fed infants were fed every third hour, with amounts increased as tolerated.

Of the 458 patients, 181 (40\%) were inborn at the Queen Silvia Children's Hospital in Gothenburg. The remaining patients were transferred from other hospitals. Outborn patients were with few exceptions diagnosed in the referring hospital by a paediatrician trained in echocardiography and then discussed with the paediatric cardiac centre via a video conference system. PGE1 was administered before and during transport when indicated. Preoperative treatment with PGE1 was administered in 79\% (361/458). The initial preoperative care at the Queen Silvia Children's Hospital was undertaken in the paediatric intensive care unit in 83/458 (18\%) infants. The remaining infants did not need initial intensive care. The proportion in each diagnostic group that received PGE1 is shown in table 1. Two hundred and six infants had definitive or potential ductal-dependent systemic circulation, consisting of the diagnoses of HLHS, interrupted aortic arch, CoA and aortic stenosis. Of them, 96\% $(198 / 206)$ were enterally fed before cardiac intervention and $85 \%(169 / 198)$ of these reached full feeds. One infant in this group developed NEC (1/206, 0.5\%). There were 103 infants with TGA (96\% on PGE1), and of these 99\% (102/103) were enterally fed before heart surgery, all reaching full feeds. One infant with TGA developed NEC (1/103, 1.0\%). Among the remaining diagnoses, 97\% (144/149) were enterally fed before heart surgery, 92\% (133/144) reached full feeds and two developed NEC (tables 1 and 2).

In total, 4 of $458(0.9 \%)$ infants developed NEC. As shown in table 2, all four reached full enteral feeds prior to cardiac surgery, met Bell's stage IIIB diagnostic criteria for NEC and three of four were born at term. ${ }^{12}$ One had ToF and was small for gestational age, born at $38+0$ weeks with birth weight of $1716 \mathrm{~g}$. This infant received a combination of breast milk and formula prior to NEC development. The second infant, born at $39+1$ weeks $(2820 \mathrm{~g})$, also had ToF and, in addition, $22 \mathrm{q} 11$ deletion syndrome, hypoparathyroidism and was vulnerable to infections due to immunodeficiency. Prior to NEC diagnosis, this infant was fed with formula only, and received no breast milk.

The third infant diagnosed with NEC was prenatally diagnosed with TGA, and born at $35+4$ weeks with a birth weight of $2750 \mathrm{~g}$. In addition to TGA, there was complicated coronary anatomy, a restrictive ventricular septal defect and subvalvular pulmonary stenosis. Therefore, it was decided to give time for growth before proceeding with cardiac surgery. By 3 weeks of age, a Rashkind septostomy was done, and by 3 months of age cardiac surgery with a Blalock-Taussig shunt. Hence, during the first 3 months of life this child had a saturation between $50 \%$ and $70 \%$. One day after surgery, there were evident signs of NEC. Bowel necrosis and perforation was found at laparotomy. This infant received full enteral feeds with formula only prior to cardiac surgery. The final surgical procedure was a total cavopulmonary communication. Of the 45 preterm infants in this study, 40 received enteral feeds before cardiac surgery, but only this one developed NEC.

A fourth infant, born at term, developed intestinal necrosis and perforation during the first hours of life. This infant was born with CoA, Vertebral defects, anal atresia, cardiac defects, 


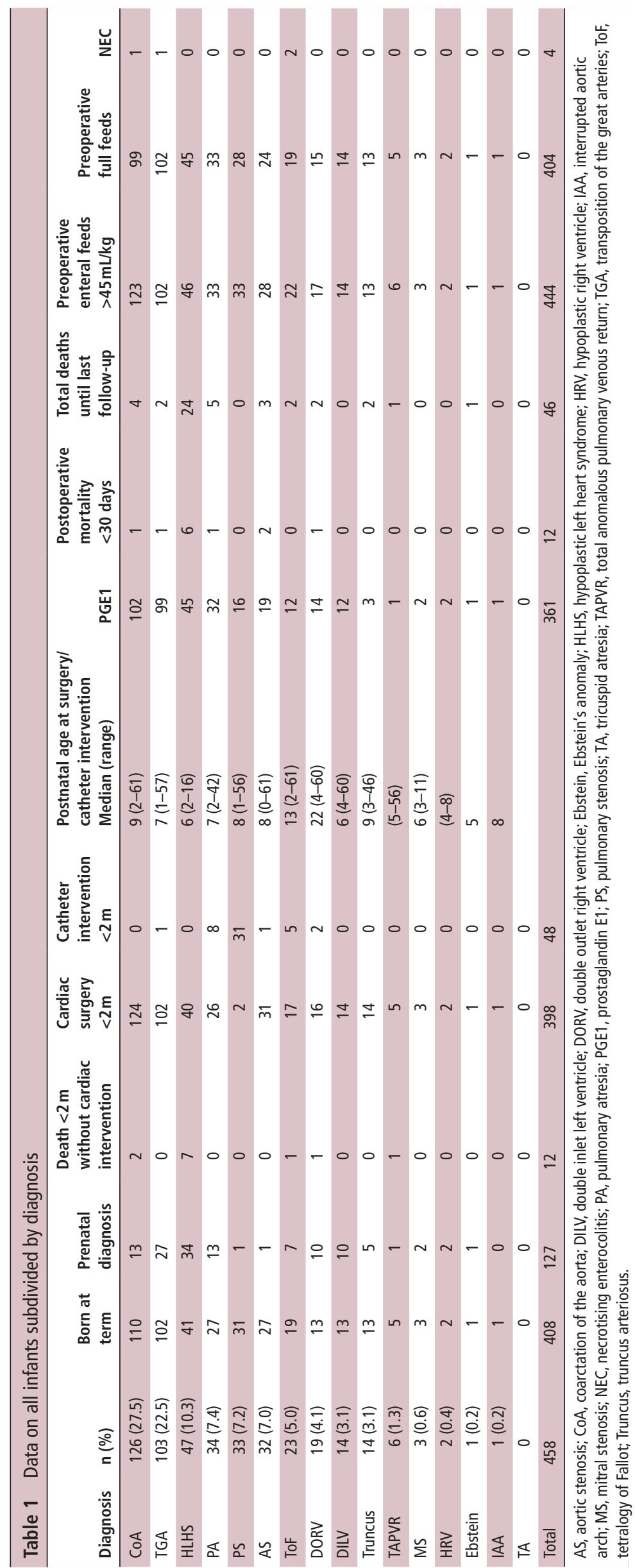




\begin{tabular}{|c|c|c|c|c|c|c|c|c|}
\hline $\begin{array}{l}\text { NEC } \\
\text { case }\end{array}$ & $\begin{array}{l}\text { Gestational age } \\
\text { at birth } \\
\text { (weeks+days) }\end{array}$ & $\begin{array}{l}\text { Birth } \\
\text { weight } \\
\text { (g) }\end{array}$ & $\begin{array}{l}\text { Main cardiac } \\
\text { diagnosis }\end{array}$ & Other significant diagnoses & $\begin{array}{l}\text { Preoperative } \\
\text { PGE1 }\end{array}$ & $\begin{array}{l}\text { Enteral feeding before } \\
\text { cardiac surgery }\end{array}$ & $\begin{array}{l}\text { Age at cardiac } \\
\text { surgery } \\
\text { (days) }\end{array}$ & $\begin{array}{l}\text { Age at NEC } \\
\text { diagnosis } \\
\text { (days) }\end{array}$ \\
\hline 1 & $38+0$ & 1716 & ToF & Intrauterine growth restriction & No & $\begin{array}{l}\text { Full feeds } \\
\text { (breast milk+formula) }\end{array}$ & 44 & 60 \\
\hline 2 & $39+1$ & 2820 & ToF & $\begin{array}{l}22 q 11 \\
\text { Hypoparathyroidism }\end{array}$ & Yes & $\begin{array}{l}\text { Full feeds } \\
\text { (formula) }\end{array}$ & 11 & 18 \\
\hline 3 & $35+4$ & 2750 & TGA & $\begin{array}{l}\text { Preterm birth. } \\
\text { Complicated coronary anatomy, } \\
\text { ventricular septal defect and } \\
\text { subvalvular pulmonary stenosis. }\end{array}$ & $\begin{array}{l}\text { Yes, for a few } \\
\text { days }\end{array}$ & $\begin{array}{l}\text { Full feeds } \\
\text { (formula) }\end{array}$ & 90 & 91 \\
\hline 4 & $40+0$ & 3098 & $\mathrm{CoA}$ & $\begin{array}{l}\text { VACTERL association, sepsis at } \\
\text { birth }\end{array}$ & Yes & $\begin{array}{l}\text { Full feeds } \\
\text { (breast milk, no feeds } \\
\text { before NEC diagnosis) }\end{array}$ & 18 & 1 \\
\hline
\end{tabular}

.COA, coarctation of the aorta; NEC, necrotising enterocolitis; PGE1, prostaglandin E1; TGA, transposition of the great arteries; ToF, tetralogy of Fallot; VACTERL, vertebral defects, anal atresia, cardiac defects, tracheo-esophageal fistula, renal anomalies, limb abnormalities.

tracheo-esophageal fistula, renal anomalies, limb abnormalities (VACTERL) association and sepsis. Abdominal signs occurred 3 hours after birth, before initiation of enteral feeding. Laparotomy showed bowel necrosis and perforation. This infant received preoperative treatment with PGE1, underwent cardiac surgery 18 days later and reached full feeds prior to cardiac surgery. Since no enteral feeds were initiated until 4 days after laparotomy and bowel resection, enteral feeding could not have been a factor contributing to development of bowel necrosis in this particular case. Furthermore, diagnosing this case with NEC can be questioned since the extremely early onset of alarming abdominal signs considerably differs from the usual pattern of the disease. When feeding was initiated this infant received only breast milk and no formula.

\section{DISCUSSION}

This study showed that in a group of 458 infants with CCHD, of whom $97 \%$ were enterally fed before cardiac intervention, the frequency of NEC was low $(n=4,0.9 \%)$. The four infants with NEC were all enterally fed prior to cardiac surgery, and all four had other risk factors such as chromosomal aberration, immunodeficiency, small for gestational age and sepsis. Three of four were born at term and one was late preterm. One term infant was diagnosed with NEC on day 1, prior to enteral feeding and cardiac surgery. The remaining three were enterally fed prior to cardiac surgery, and developed NEC after the procedure. Prior to development of NEC, all three infants received formula feeding, either formula only (two infants) or mixed with breast milk (one infant). Thus, there were no cases of preoperative NEC after initiation of preoperative enteral feeds which suggests safety of this practice. Our study covers the period from birth until discharge from hospital, therefore the risk of undetected cases of NEC in our study is small.

Frequency of NEC among neonates with CCHD and the role of preoperative enteral feeds

De la Torre $e t a l^{10}$ found a NEC frequency of $7.3 \%$ among 935 neonates with CCHD. Lau $e t a l^{9}$ studied neonates with CCHD grouped by Risk Adjustment for Congenital Heart Surgery and 61/1811 (3.4\%) developed NEC. Eighty-six per cent were on enteral feeds at the time of NEC diagnosis. McElhinney et $a l^{11}$ found a similar NEC frequency (3.3\%) in a group of 643 neonates with $\mathrm{CCHD}, 7 \%$ had received enteral feeds preoperatively. Becker $e a l^{13}$ found NEC in $0.3 \%$ of 6710 neonates with ductal-dependent CCHD of whom $14 \%$ were enterally fed while on PGE1. However, in that study, only NEC developing during ongoing PGE1 treatment, before cardiac surgery, was registered. Iannucci et $a l^{14}$ showed a NEC frequency of $3 \%$ among 1551 infants with CCHD. Eighty-two per cent were diagnosed in the postoperative period. This is consistent with our study where three of four NEC cases were postoperative. In a recent study, Day et al could not show any association between enteral feeding and NEC in infants with duct-dependent congenital heart disease. ${ }^{15}$ They found a NEC incidence in their cohort of $10.1 \%$.

Scahill et $a l^{8}$ reported that $61 \%$ of neonates who required cardiac surgery were enterally fed before surgery and $9 \%$ developed NEC. The study showed no difference in the prevalence of NEC between the groups with and without preoperative enteral feeding. In a study by Natarajan et al, ${ }^{16} 62$ of 67 neonates with CCHD were enterally fed before cardiac surgery, of them $75 \%$ (47/62) obtained at least $100 \mathrm{~mL} / \mathrm{kg} /$ day and $35 \%(22 / 62)$ full feeds. The incidence of NEC was 3\% (2/67). The rate of preoperative enteral feeding is comparable to our cohort.

In summary, the previously reported frequency of NEC in infants born with CCHD varies between $3 \%$ and $9 \%$, with no obvious relationship to preoperative feeding practices. In our study, the frequency of NEC was much lower despite routine preoperative feeding and three of four cases had other risk factors for NEC.

There is no uniform definition of CCHD which complicates comparison between different studies. However, the majority of the neonates in this study had well-defined critical cardiac diagnoses such as HLHS, aortic arch obstruction, TGA and pulmonary atresia. Preoperative circulatory instability with hypoxia, poor intestinal perfusion and acidosis likely increases the risk of NEC in neonates with CCHD. ${ }^{13} 1718$ Although this Swedish cohort includes only infants with CCHD we cannot exclude that they were in a more stable condition preoperatively compared with published cohorts with a higher frequency of NEC. The proportion of neonates with a prenatal diagnosis was rather low overall, but a well-developed referral and transport system in Sweden for infants with suspected CCHD, and access to paediatricians with some training in cardiology and paediatric echocardiography in almost all delivery units may have contributed to the low frequency of NEC compared with previous studies.

\section{Ductal-dependent systemic circulation and NEC}

HLHS, critical aortic stenosis, interrupted aortic arch and CoA are cardiac defects in which systemic circulation may remain 
compromised even after initiation of PGE1. Previous studies have shown that the risk of NEC is increased in infants with these diagnoses compared with other CCHD. Reduced mesenteric perfusion is thought to be the underlying cause of this association, ${ }^{131718}$ and it is in infants with these diagnoses that the practice of avoiding preoperative enteral feeding is most widespread. ${ }^{71}$ ElHassan et $a l^{17}$ found that NEC developed in $6 \%$ of 5720 neonates with HLHS, which provides a benchmark of the incidence in that group. The proportion receiving enteral feeds before surgery was not described. McElhinney et $a l^{11}$ reported a similar NEC frequency (7\%) among infants with HLHS. In our study, 46 of 47 infants with HLHS were enterally fed before cardiac surgery and there were no cases of NEC. In our cohort of infants with ductal-dependent systemic circulation 96\% (198/206) were enterally fed before cardiac intervention and one infant was diagnosed with NEC. This indicates that the practice of not offering enteral feeds before cardiac surgery to infants with CCHD and ductal-dependent systemic circulation needs to be re-evaluated. Breast milk constitutes a protective factor against the development of NEC, ${ }^{2021}$ which is an advantage compared with TPN. It also enhances the infant's innate immune system by facilitating pathogen recognition and antiinflammatory response. ${ }^{22} 23$ In addition, by increasing enteral feeds, the risks associated with prolonged TPN are avoided. All this should be of benefit to these infants who are at risk of developing postoperative severe bacterial infections. ${ }^{24}$ As described in a review by Niño et al, multiple randomised clinical trials have now validated the observation that breast milk reduces the incidence of NEC. ${ }^{25}$ Human milk contains a variety of beneficial factors, among which several have been shown to reduce NEC incidence. Whether the development of NEC in association with formula feeding is due to an injurious agent in infant formula, or the lack of a protective component only present in breast milk remains to be determined. ${ }^{25}$ The use of standardised feeding guidelines has been proven to be effective to reduce the incidence and severity of NEC. ${ }^{25}$ Several studies from infants born preterm show that it is safe and even beneficial with early introduction and fast advancement of enteral breast milk. ${ }^{26} 27$ An initial fasting period is not recommended in these studies on preterm infants. ${ }^{26} 27$ The effects on intestinal maturation in combination with a shorter need for parenteral nutrition are some of the positive effects noted.

\section{Strengths and limitations}

The study presents a large cohort of neonates with CCHD, and information on enteral feeding before cardiac surgery was carefully investigated.

This study is limited by the inherent limitations of retrospective studies. We used the ICD-10 code to identify cases of NEC. Thus, the results rely on correct diagnostic coding. However, we crosschecked against the paediatric surgery register which should minimise the risk of under-reporting. Neonates who died at a referring hospital or after admission to our hospital with undiagnosed CCHD (detected only at a postmortem examination) were not searched for. They should however be very few, if any.

\section{CONCLUSION}

This study has demonstrated that preoperative enteral feeding in infants with CCHD is safe in our institution. Of the four NEC cases in our entire cohort there were no cases of preoperative NEC after initiation of preoperative enteral feeds. This includes 206 infants with ductal-dependent systemic blood flow.
We speculate that the Swedish practice to provide preoperative enteral feeding in these patients does not increase the risk of NEC.

Acknowledgements We thank Dr Janet Lang, Great Ormond Street Hospital, London, for expert language review.

Contributors MM and AE conceptualised and designed the study, advised on the data analysis and interpretation of results, and reviewed and revised the manuscript. $\mathrm{KN}$ carried out the study design and data collection and analysis and drafted the initial manuscript. KL contributed to drafting the study design and critically reviewed and revised the manuscript for important intellectual content. All authors approved the final manuscript as submitted and agree to be accountable for all aspects of the work.

Funding This study was partly financed by Region Västra Götaland, Sahlgrenska University Hospital, Queen Silvia Children's Hospital, Department of Pediatrics, Gothenburg, Sweden. It was also financed by grants from the Swedish state under the agreement between the Swedish government and the county councils, the ALF agreement (117661). MM was supported by the Swedish Heart and Lung Foundation.

Competing interests None declared.

Patient consent for publication Not required.

Ethics approval The study was approved by the Regional Ethical Review Board in Gothenburg (study code T714-17).

Provenance and peer review Not commissioned; externally peer reviewed.

Data availability statement Data are available upon reasonable request. All data relevant to the study are included in the article or uploaded as supplementary information. Deidentified data will be available upon reasonable request. Data are kept at a repository. Contact details: Anders Elfvin, anders.elfvin@vgregion.se. Phone:+46313438073.

Open access This is an open access article distributed in accordance with the Creative Commons Attribution Non Commercial (CC BY-NC 4.0) license, which permits others to distribute, remix, adapt, build upon this work non-commercially, and license their derivative works on different terms, provided the original work is properly cited, appropriate credit is given, any changes made indicated, and the use is non-commercial. See: http://creativecommons.org/licenses/by-nc/4.0/.

\section{ORCID iD}

Anders Elfvin http://orcid.org/0000-0002-1912-9563

\section{REFERENCES}

1 Neu J, Walker WA. Necrotizing enterocolitis. N Eng/ J Med 2011;364:255-64.

2 Shulhan J, Dicken B, Hartling L, et al. Current knowledge of necrotizing enterocolitis in preterm infants and the impact of different types of enteral nutrition products. $A d v$ Nutr 2017:8:80-91.

3 Eaton S, Rees CM, Hall NJ. Current research in necrotizing enterocolitis. Early Hum Dev 2016:97:33-9.

4 Berman L, Moss RL. Necrotizing enterocolitis: an update. Semin Fetal Neonatal Med 2011;16:145-50

5 Qian T, Zhang R, Zhu L, et al. [Analysis of clinical characteristics of necrotizing enterocolitis in term infants]. Zhonghua Yi Xue Za Zhi 2016;96:1766-72.

6 Lu Q, Cheng S, Zhou M, et al. Risk factors for necrotizing enterocolitis in neonates: a retrospective case-control study. Pediatr Neonatol 2017;58:165-70.

7 Howley LW, Kaufman J, Wymore E, et al. Enteral feeding in neonates with prostaglandin-dependent congenital cardiac disease: international survey on current trends and variations in practice. Cardiol Young 2012;22:121-7.

8 Scahill CJ, Graham EM, Atz AM, et al. Preoperative feeding neonates with cardiac disease. World J Pediatr Congenit Heart Surg 2017;8:62-8.

9 Lau PE, Cruz SM, Ocampo EC, et al. Necrotizing enterocolitis in patients with congenital heart disease: a single center experience. J Pediatr Surg 2018;53:914-7.

10 De La Torre CA, Miguel M, Martínez L, et al. [The risk of necrotizing enterocolitis in newborns with congenital heart disease. a single institution-cohort study]. Cir Pediatr 2010;23:103-6.

11 McElhinney DB, Hedrick HL, Bush DM, et al. Necrotizing enterocolitis in neonates with congenital heart disease: risk factors and outcomes. Pediatrics 2000;106:1080-7.

12 Bell MJ, Ternberg JL, Feigin RD, et al. Neonatal necrotizing enterocolitis. therapeutic decisions based upon clinical staging. Ann Surg 1978;187:1-7.

13 Becker KC, Hornik CP, Cotten CM, et al. Necrotizing enterocolitis in infants with ductal-dependent congenital heart disease. Am J Perinatol 2015;32:633-8.

14 Iannucci GJ, Oster ME, Mahle WT. Necrotising enterocolitis in infants with congenital heart disease: the role of enteral feeds. Cardiol Young 2013;23:553-9.

15 Day TG, Dionisio D, Zannino D, et al. Enteral feeding in duct-dependent congenital heart disease. J Neonatal Perinatal Med 2019;12:9-12. 


\section{Original research}

16 Natarajan G, Reddy Anne S, Aggarwal S, et al. Enteral feeding of neonates with congenital heart disease. Neonatology 2010;98:330-6.

17 ElHassan NO, Tang X, Gossett J, et al. Necrotizing enterocolitis in infants with hypoplastic left heart syndrome following stage 1 palliation or heart transplant. Pediatr Cardiol 2018;39:774-85.

18 Stapleton GE, Eble BK, Dickerson HA, et al. Mesenteric oxygen desaturation in an infant with congenital heart disease and necrotizing enterocolitis. Tex Heart Inst J 2007:34:442-4.

19 Johnson BA, Mussatto K, Uhing MR, et al. Variability in the preoperative management of infants with hypoplastic left heart syndrome. Pediatr Cardiol 2008:29:515-20.

20 Cruz Ddela, Bazacliu C. Enteral feeding composition and necrotizing enterocolitis. Semin Fetal Neonatal Med 2018;23:406-10.

21 Lucas A, Cole TJ. Breast milk and neonatal necrotising enterocolitis. Lancet 1990:336:1519-23.
22 Jakaitis BM, Denning PW. Human breast milk and the gastrointestinal innate immune system. Clin Perinatol 2014;41:423-35.

23 Cacho NT, Lawrence RM. Innate immunity and breast milk. Front Immunol 2017;8:584.

24 García H, Cervantes-Luna B, González-Cabello H, et al. Risk factors for nosocomial infections after cardiac surgery in newborns with congenital heart disease. Pediatr Neonatol 2018;59:404-9.

25 Niño DF, Sodhi CP, Hackam DJ. Necrotizing enterocolitis: new insights into pathogenesis and mechanisms. Nat Rev Gastroenterol Hepatol 2016;13:590-600.

26 Belling-Dierks F, Glaser K, Wirbelauer J, et al. Does rapid enteral feeding increase intestinal morbidity in very low birth weight infants? A retrospective analysis. J Matern Fetal Neonatal Med 2017;30:2690-6.

27 SIFT Investigators Group. Early enteral feeding strategies for very preterm infants: current evidence from Cochrane reviews. Arch Dis Child Fetal Neonatal Ed 2013;98:F470-2. 